\title{
Metastatic carcinoma to glioma: a report of three cases with a critical review of the literature
}

\author{
SVERRE J MÖRK, * LUCIEN J RUBINSTEIN \\ From the Division of Neuropathology, Department of Pathology, University of Virginia School of Medicine, \\ Charlottesville, VA, USA
}

SUMMARY Three cases are reported of primary bronchial carcinoma with metastatic deposits in an intracranial glioma (two cerebral astrocytomas and one fourth ventricle ependymoma). The rarity of this phenomenon is emphasised and the literature critically reviewed.

Metastasis of cancer to cancer is a well-documented phenomenon, including the metastasis of a neoplasm originating outside the central nervous system into a primary intracranial tumour. In the great majority of the latter cases the intracranial tumour was a meningioma. ${ }^{1-10}$

In this paper we draw attention to the occasional development of a metastatic carcinomatous deposit in an intracranial glioma. Cases of this nature have so far seldom been completely or convincingly documented (see discussion). Three such unquestionable cases will be described.

\section{Case reports}

\section{Case 1 (C2940)}

Clinical summary A 44 year old male had experienced cough and fatigue for 2 months, when a biopsy from the lower lobe of the left lung revealed a primary bronchial carcinoma. A left pneumonectomy was performed. Three months later computed tomography and radionuclide scans disclosed metastic deposits in the liver and brain. Radiation to the brain was started, but the patient died from respiratory arrest 2 weeks later.

Pathological findings Necropsy revealed multiple subpleural metastases in the right lung and numerous deposits in the right adrenal gland, liver and mesentery. Their microscopic features were those of a poorly differentiated meta-

*Present address: The Gade Institute, Department of Pathology, University of Bergen Medical School, Haukeland Hospital, Bergen, Norway.

Address for reprint requests: Lucien J Rubinstein, MD, Division of Neuropathology, Department of Pathology, University of Virginia School of Medicine, Charlottesville, VA 22908, USA.

Received 6 March 1987.

Accepted 20 May 1987 static adenocarcinoma consistent with a bronchial origin. In the central nervous system several round and finely granular lesions, about $10 \mathrm{~mm}$ in diameter, were present bilaterally in the frontal lobes and cerebellar hemispheres. In addition a finely granular, velvety and somewhat shiny mass (measuring up to $5 \mathrm{~cm}$ in its largest diameter) was found in the wall of the anterior horn of the left lateral ventricle, anterior fornix, septum lucidum and genu of the corpus callosum. If extended into the right basal ganglia. Microscopically the large central cerebral lesion was mainly composed of diffusely infiltrating pleomorphic, occasionally multi nucleated astrocytes with hyperchromatic nuclei, therefore typical of anaplastic astrocytoma. Within this glioma, a ciro cumscribed tumour nodule composed of large cells with a epithelial trabecular arrangement, abundant cytoplasm and heavily stained, irregular nuclei was found. These cells were cytologically identical with the pulmonary bronchogenic carcinoma, thus constituting distinct islands of poorly differentiated adenocarcinoma in an anaplastic astrocytoma (fig 1). Other sections from the brain remote from the glioma showed the typical lesions of metastatic adenocarcinoma.

\section{Case 2 (C357)}

Clinical summary A 58 year old man developed signs of a posterior fossa tumour. A craniotomy revealed an ependymoma of the fourth ventricle. Following postoperative radiation, the patient remained well for 14 months. He then became lethargic and weak, and complained of anorexia and hoarseness. Neurological examination revealed bilateral sixth nerve palsy, nystagmus in all fields and depressed deep tendon reflexes bilaterally. There was suggestive weakness of the left leg and a questionable weakness of the 5th cranial nerve. In hospital he developed fever, increasing respiratory difficulty and died 14 days after the onset of these symptoms. Brief mention of this case has previously been made. ${ }^{11}$

Pathological findings At necropsy a central, left lung tumour was found, associated with widespread gross metastases to the local lymph nodes, right lung, pleura, liver, adrenal glands, bones, spinal meninges and brain. In the central nervous system, a $1.0 \times 1.5 \mathrm{~cm}$ granular tumour was seen attached to the dura and compressing the floor of the 4th ventricle, with extension.in the midline below the cerebellar 


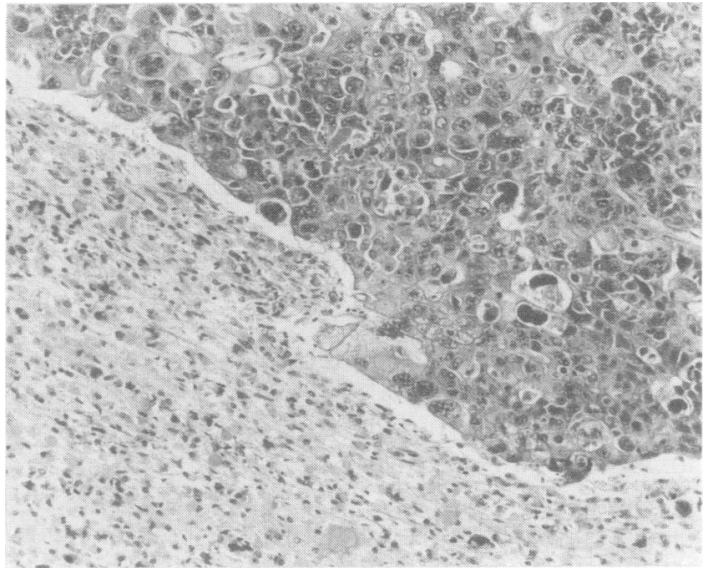

Fig 1 (Case 1) Poorly differentiated adenocarcinoma adjacent to anaplastic astrocytoma $(H \& E \times 90)$.

hemispheres into the cisterna magna. Microscopically, the pulmonary tumour was a poorly differentiated small-cell bronchogenic carcinoma with extensive metastases. Sections from the lesion in the posterior fossa revealed ependymoma harbouring discrete clusters of small cells (fig 2a) with sparse cytoplasm, hyperchromatic oval nuclei, mitotic figures and single cell necrosis, typical of oat-cell carcinoma. Occasionally, metastatic tumour cells were found within venules of the ependymoma (fig $2 b$ ).

\section{Case 3 (C274)}

Clinical summary A 38 year old man had a left upper pulmonary lobectomy for a tumour that a biopsy showed to be adenocarcinoma. Clinical signs of an intracranial expanding lesion necessitated a craniotomy that revealed a gross metastasis in the left temporal lobe. Six weeks after discharge he was readmitted with a presumptive diagnosis of recurrent cerebral tumour (metastasis) because of convulsive seizures and right-sided weakness. Before radiotherapy could be initiated the patient's condition rapidly deteriorated and he died $4 \frac{1}{2}$ months after the thoracotomy.

Pathological findings Biopsy from the lesion in the left temporal lobe proved it to be metastatic adenocarcinoma. Necropsy disclosed metastic deposits in the right lung, liver, pancreas, right adrenal gland, and kidneys. In the brain two masses were present, one sharply circumscribed in the left temporal lobe and the other less well-defined in the left occipital lobe. Microscopic examination of tissue from the

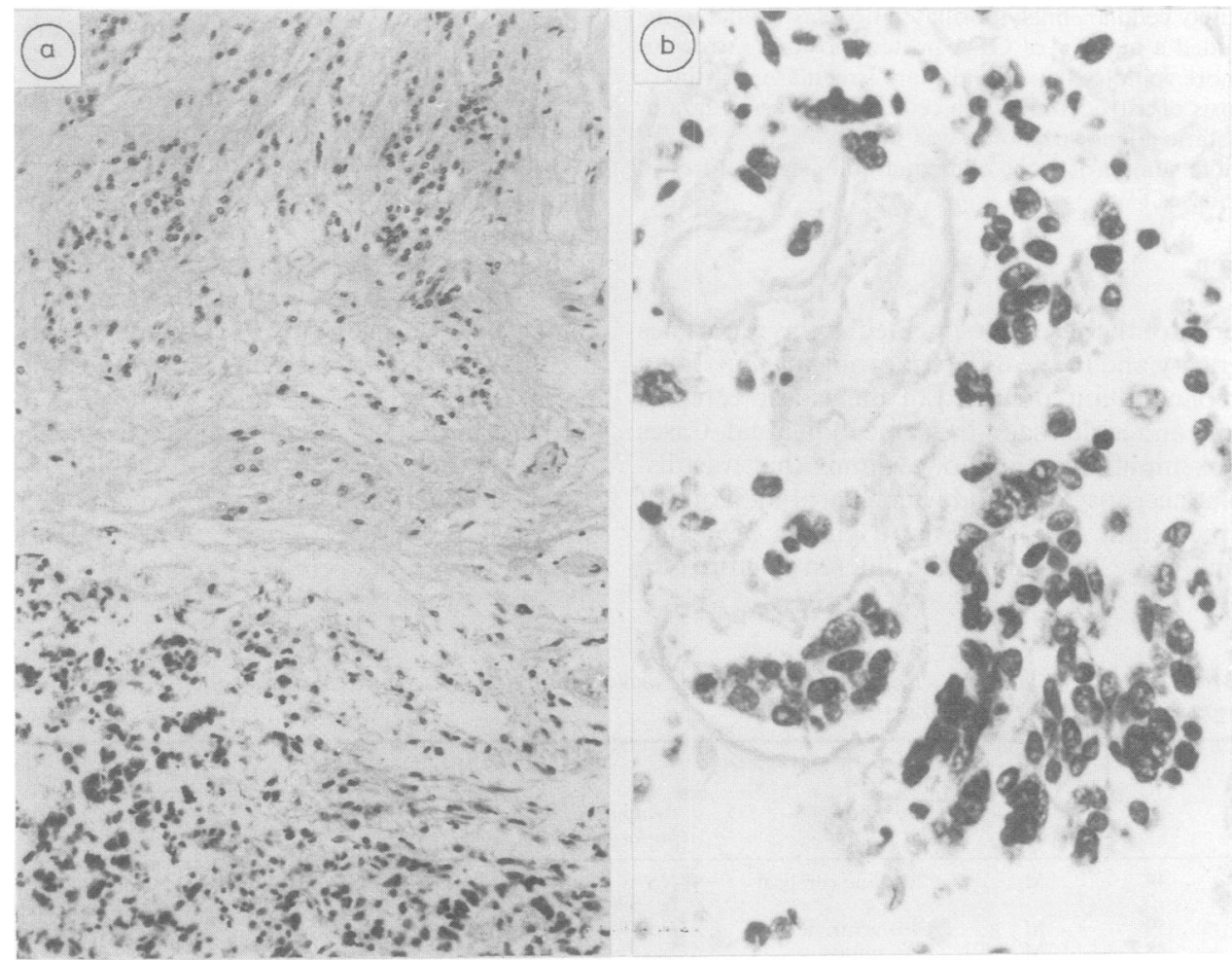

Fig 2 (Case 2) (a) Fourth-ventricle ependymoma containing tumour cells consistent with spread from oat-cell carcinoma (lower half). $H \& E \times 125$. (b) Higher magnification showing clusters of oat cell carcinoma cells, some of them in a thin-walled blood vessel (lower left) $(H \& E \times 400)$. 


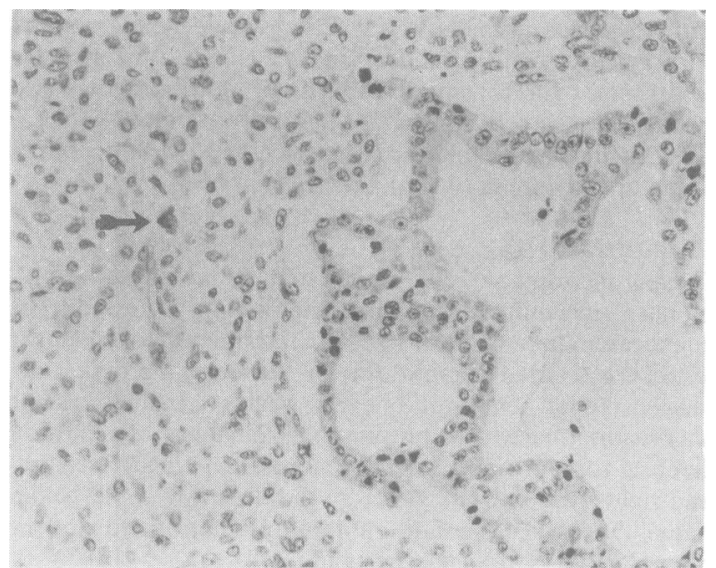

Fig 3 (Case 3) Metastatic adenocarcinoma adjacent to moderately cellular astroxytoma. Occasional positivity of astrocytic tumour cell (arrow) for GFA protein (immunoperoxidase stain for GFA protein counterstained with haematoxylin $\times 150$ ).

latter location disclosed trabeculae and irregular tongues of metastatic cuboidal and columnar carcinoma surrounded by a moderately cellular, finely fibrillated neoplastic glial tissue that included a number of GFA protein-positive astrocytes amidst more spindle-shaped and more irregular cells (fig 3 ). A diagnosis of astrocytoma with cellular anaplasia containing metastatic adenocarcinoma was made.

The table summarises the clinicopathological features of the three cases.

\section{Discussion}

The interest of the cases documented in this report lies in their rarity and in the different problems illustrated by the concomitant presence of metastatic cerebral carcinoma and a glioma in the same individual. Cases 1 and 3 exemplify instances of a glioma that was discovered at necropsy only and which harboured one of several metastatic deposits from a known bronchial carcinoma. Case 2 presented the different picture of a patient from whom a primary intracranial glioma had been subtotally removed and who subsequently developed metastases from an unsuspected bronchial carcinoma: the residual intracranial tumour was found at necropsy to harbour metastatic tumour deposits: This case is of clinical interest in that renewed neurological signs attributable to brainstem and cerebellar involvement could have been due to the unsuspected presence of carcinomatous deposits in the ependymoma.

Only one example of glioblastoma and two of oligodendroglioma have so far been reported as har- $\bar{O}$ bouring metastatic tumour from respectively thyroid $\overline{0}$ carcinoma, ${ }^{12}$ breast carcinoma, ${ }^{13}$ and melanoma. ${ }^{14} \frac{}{\mathrm{c}}$ Critical review of those reports suggests that only $\overparen{\otimes}$ Strang's ${ }^{13}$ case, that of a mammary carcinoma metastasising into an oligodendroglioma, is probably acceptable. However, anatomical verification is lacking in that case. The case reported by Posnikoff and Stratford $^{12}$ is in our view questionable. They described a grade IV astrocytoma containing highly cellular foci which they interpreted as "carcinoma cells" and which more likely represent epithelial-like formations of anaplastic glioma cells, like those $i$ reported by Kepes et $a l^{15}$ and by Galloway and on Roessmann. ${ }^{16}$ As illustrated in their figures and as admitted in the text, the anaplastic cell cluster described by Posnikoff and Stratford did not resem $2-$ ble the structure of a papillary carcinoma which the encountered on postmortem examination as an ince dental microscopic finding in the grossly atrophis thyroid. Furthermore, metastatic deposits were no found in any other site of the body. Neither can the case of Farnsworth, ${ }^{14}$ reported as a regressive melanoma metastasising to an oligodendroglioma, be accepted without reservations as the glioma was poorly documented and the capacity of a metastatic intracerebral melanoma to mimic the appearances of glioma is well-known. ${ }^{17}$

The three cases reported here are not open to those strictures because (1) complete necropsy documentation on both the primary carcinoma and the meta-

Table Main features of patients with primary bronchial carcinoma and metastasis to an intracranial glioma. Post-mortem examination was performed in all cases

\begin{tabular}{|c|c|c|c|c|c|c|}
\hline \multirow[b]{2}{*}{ Patient } & \multirow[b]{2}{*}{$\begin{array}{l}\text { Age } \\
(y r)\end{array}$} & \multirow[b]{2}{*}{ Sex } & \multirow[b]{2}{*}{$\begin{array}{l}\text { Location } \\
\text { of glioma }\end{array}$} & \multirow[b]{2}{*}{$\begin{array}{l}\text { Craniotomy } \\
\text { performed }\end{array}$} & \multicolumn{2}{|l|}{ Histology } \\
\hline & & & & & Glioma & $\begin{array}{l}\text { Metastasis } \\
\text { in glioma }\end{array}$ \\
\hline $1(\mathrm{C} 2940)$ & 44 & $\mathbf{M}$ & Midline cerebral & No & Anaplastic astrocytoma & $\begin{array}{l}\text { Poorly differentiated } \\
\text { adenocarcinoma }\end{array}$ \\
\hline $\begin{array}{l}2(\mathrm{C} 357) \\
3(\mathrm{C} 274)\end{array}$ & $\begin{array}{l}59 \\
38\end{array}$ & $\begin{array}{l}\mathbf{M} \\
\mathbf{M}\end{array}$ & $\begin{array}{l}\text { 4th ventricle } \\
\text { Occipital }\end{array}$ & $\begin{array}{l}\text { Yes* } \\
\text { Yest }\end{array}$ & $\begin{array}{l}\text { Ependymoma } \\
\text { Moderately anaplastic } \\
\text { astrocytoma }\end{array}$ & $\begin{array}{l}\text { Oat-cell carcinoma } \\
\text { Adenocarcinoma }\end{array}$ \\
\hline
\end{tabular}

* Craniotomy for 4 th ventricle ependymoma.

†Craniotomy for cerebral metastasis. 
static deposits is available; (2) the metastases were multiple and occupied both the extraneural tissues and parts of the brain uninvolved by the concomitant glioma; and (3) in all cases the glioma and the included metastasis were cytologically quite distinct.

No causal relationship can be invoked for the existence of two different neoplasms in the same patient in these cases; the presence of a primary glioma and of a visceral malignancy should be regarded as coincidental. Data on the aetiology and incidence of multiple primary cancers are not readily available, although the subject has recently been extensively reviewed. ${ }^{18}$ Generally, the chances of a patient having multiple primary neoplasms increase with age and length of survival. In view of the high incidence of bronchogenic carcinoma and the frequency of central nervous system (CNS) metastasis in this form of cancer it is perhaps surprising that documentation of a metastasis to a glioma should be so exceptional. Necropsy series indicate a high frequency in the incidence of cerebral metastases from bronchial carcinoma. In a necropsy series from the Montefiore Hospital, New York, of 3359 patients with primary malignant tumours outside the CNS, $34.4 \%$ of the patients who died of pulmonary carcinoma had cerebral metastases. ${ }^{19}$ Among the 71,006 males and 24,080 females who died of lung cancer in the US in $1978^{20}$ the number of patients with CNS metastases can be estimated to be about 30,000 . Another major contributor to metastatic cerebral disease is mammary carcinoma, which was responsible for 34,600 deaths among US women in 1979:20 here the frequency of cerebral metastasis was estimated at about $25 \% .{ }^{21}$ In patients with malignant melanoma $75 \%$ have been recorded to have CNS metastases at necropsy. ${ }^{22}$

Most reported cases of cancer metastasising to an intracranial neoplasm have so far been examples of breast, lung or prostatic carcinoma into meningiomas ${ }^{9}$ and schwannomas. ${ }^{8}$ Hypophyseal adenoma has also been reported to be the intracranial site of a tumour-to-tumour metastasis. ${ }^{7}$ We have been privileged to examine an example of metastatic prostatic adenocarcinoma into a recurrent cerebellar capillary hemangioblastoma in a 76 year old male (courtesy of Dr RO Barnard, London).

It is, however, possible that the manifestations of tumour-to-tumour metastasis, as exemplified by our cases of metastatic carcinoma into a glioma, may becomes less uncommon in view of the high frequency of cerebral metastases from the most common forms of malignancy, the improved therapeutic control of neoplastic diseases and the prolonged survival of cancer patients.

We thank Dr M Montes, Buffalo, NY and Dr U Tomiyasu, Los Angeles, CA, for kindly referring pathological material to us, for providing clinical information and for allowing publication of their cases. We also thank Ms Ursula W Bunch for photographic assistance.

Dr Mörk is supported by the Rebekka Ege Hegermann Memorial Legacy and the Gade Legacy, Bergen, and by the Norwegian Cancer Society, Oslo.

\section{References}

1 Fried BM. Metastatic inoculation of meningioma by cancer cells from a bronchiogenic carcinoma. Am J Pathol 1930;6:47-52.

2 Bernstein SA. Uber Karzinommetastase in einem Duraendotheliom. Zbl Allg Pathol 1933;58:163-6.

3 Ortega P Jr, Li IY, Shimkin M. Metastasis of neoplasms to other neoplasms. Ann West Med Surg 1951;5:601-9.

4 Störtebecker TP. Metastatic hypernephroma of the brain from a neurosurgical point of view: a report of 19 cases. $J$ Neurosurg 1951;8:185-97.

5 Osterberg DH. Metastases of carcinoma to meningioma. J Neurosurg 1957;14:337-43.

6 Wallach JB, Edberg S. Metastases of cancer to primary intracranial tumor. Arch Neurol 1959;1:191-4.

7 Richardson JF, Katayama I. Neoplasm to neoplasm metastasis. An acidophilic adenoma harboring metastic carcinoma: case report. Arch Pathol 1971;91:135-9.

8 Chambers PW, Davis RL, Blanding JD, Buck FS. Metastases to primary intracranial meningiomas and neurilemomas. Arch Pathol Lab Med 1980;104:350-60.

9 Lodrini S, Savoiardo M. Metastases of carcinoma to intracranial meningioma: report of two cases and review of the literature. Cancer 1981;48:2668-73.

10 Schmitt HP. Metastases of malignant neoplasms to intracranial tumours: the "tumour-in-a-tumour" phenomenon. Case report. Virchows Arch [Pathol Anat] 1984;405:155-60.

11 Russell DS, Rubinstein LJ. Pathology of Tumours of the Nervous System, ed 4. London: Edward Arnold Ltd, 1977, p 358.

12 Posnikoff J, Stratford J. Carcinoma metastasis to malignant glioma. Arch Neurol 1960;5:559-63.

13 Strang RR. Metastasis of breast carcinoma to an intracerebral oligodendroglioma. Zentbl Neurochir 1965;25:206-9.

14 Farnsworth J. Regressing melanoma metastasizing to an oligodendroglioma. Pathology 1972;4:253-7.

15 Kepes JJ, Fulling KH, Garcia JH. The clinical significance of "adenoid" formations of neoplastic astrocytes, imitating metastatic carcinoma, in gliosarcomas. A review of five cases. Clinical Neuropathol 1982;4:139-50.

16 Galloway PG, Roessmann U. Anaplastic astrocytoma mimicking metastatic carcinoma. Am J Surg Pathol 1986;10:728-32.

17 Rubinstein LJ. Tumors of the Central Nervous System. Atlas of Tumor Pathology, second series, fasc 6. Washington: Armed Forces Institute of Pathology 1972; $\mathrm{p} 328$.

18 Stoll BA (ed). Risk Factors and Multiple Cancer. New Horizons in Oncology Vol. 3. New York: John Wiley \& Sons, 1984.

19 Takakura K, Sano K, Hojo S, Hirano A. Metastatic Tumours of the Central Nervous System. Tokyo: Igaku-Shoin, 1982.

20 US Bureau of the Census, Statistical Abstract of the United States: 1982-1983 (103rd Edition). Washington DC, 1982.

21 Aronson SM, Garcia JH, Aronson BE. Metastic neoplasms of the brain: their frequency in relation to age. Cancer 1964;17: 558-63.

22 Amer MH, Al-Sarraf M, Baker LH, Vaitkevicius VK. Malignant melanoma and central nervous system metastases. Incidence, diagnosis, treatment and survival. Cancer 1978;42:660-8. 